\title{
Mide nöroendokrin tümör: olgu sunumu
}

\author{
Gastric neuroendocrine tumor: a case report
}

Ferzan AYDIN ${ }^{1}$, Ahmet UYANIKOĞLU² ${ }^{2}$ Necati YENICE ${ }^{2}$, Rıza ALTUNBAŞ ${ }^{1}$, Hüseyin DURSUN ${ }^{1}$, M. Akif IZGI ${ }^{1}$, Osman YÜKSEKYAYLA ${ }^{1}$, Sezen KOÇARSLAN ${ }^{3}$

Harran Üniversitesi, Tip Fakültesi, ${ }^{1}{ }_{\text {Ç }}$ Hastalılan Anabilim Dah, ${ }^{2}$ Gastroenteroloji Bilim Dall, ${ }^{3}$ Patoloji Anabilim Dalı, Şanluurfa

Mide nöroendokrin tümörler nadir tümörlerdir. Çoğu zaman semptom vermeyip tesadüfen tespit edilmektedir. Bu olguda asemptomatik, tesadüfen tespit edilen mide nöroendokrintümör olgusu sunulacaktır.

Anahtar kelimeler: Nöroendokrin tümör, mide

\section{GİRİs}

Nöroendokrin tümörler (NET) nadir tümörlerdir. Mide tümörlerinin \%l'inden azını oluştururlar. Mide yerleşimli NET ise gastrointestinal nöroendokrin tümörler içerisinde $\% 6$ gibi çok daha küçük bir grubu oluşturur (1). Nonfonksiyonel tümörler erken dönemde semptom vermezken, tümörün büyümesi ve kitle etkisi ile karın ağrısı, ikter, bulantı ve kusma gibi semptomlara neden olurlar. (2). Bu yazıda asemptomatik, tesadüfen tespit edilen mide NET olgusu sunulmuştur.

\section{OLGU SUNUMU}

39 yaşında bayan hasta dispeptik şikayetler ile gastroenteroloji polikliniğine müracaat etti. Özgeçmişinde 10 ylldan uzun süre proton pompa inhibitörü (PPI) kullanımı olduğu ögrenildi. Fizik muayenesinde ve laboratuvar tetkiklerinde özellik yoktu. Hastanın semptomlarının uzun süreli olması nedeniyle gastroskopi yapıldı. Gastroskopide fundusta 1 cm'lik ve 0,5 cm'lik 2 adet polip görüldü. Fundusta mukoza atrofik görünümlü, antral mukoza hiperemik ve ödemli idi. Biyopsi forsepsi ile polipektomi yapılarak materyal patolojiye gönderildi. Patoloji tarafından iyi diferansiye NET, tümör dışı alanlarda intestinal metaplazi ve Helicobacter pylori varlığ olarak raporlandı (Resim 1-4). Çekilen batın bilgisayarlı tomografide metastaz saptanmadi. Hastaya Helicobacter pylori eradikasyon tedavisi başlandı. 6 ay sonra kontrol gastroskopisi planlandı. Gastroenteroloji polikliniğinden takip önerildi.

\section{TARTIŞMA}

NET'ler vücudun herhangi bir yerinde nöroendokrin sistemden köken alan tümörlerdir. NET insidansı 0.2/100.000 kişi
Gastric neuroendocrine tumors are rare. They are usually detected incidentally and mostly asymptomatic in diagnosis. In this case report we present an incidentally detected asymptomatic gastric neuroendocrine tumor.

Key words: Neuroendocrine tumor, gastric

olup tüm kanserlerin \%0.5'ini oluşturur (3). NET'lerin üçte ikisi gastrointestinal sistemde, dörtte biri akciğerde, diğerleri ise diğer endokrin dokularda görülür. Gastrointestinal NET, 2/100.000 olgu/yll insidansına sahip nadir tümörlerdir (1). Gastrointestinal kanalda en sik ileum, apendiks ve rektumda görülür. Olguların \%6'sı gibi küçük bir kısmında mide tutulumu vardır $(2,4)$. Ancak son yllarda mide NET'lerde bir artış görülmektedir. Bu gerçek bir artış olabileceği gibi, endoskopik inceleme sıklığının artması, bu tür lezyonların tanınması ve patolojik tanı koyma yöntemlerinin daha etkin kullanılmasına bağlı görece bir artış da olabilir (5). Bu olgu nadir görülen bir antite olduğundan sunulmuştur.

Üç tip mide NET tanımlanmıştır. Tipl ve Tip2 mide NET hipergastrinemi ile ilişkilidir ve genellikle düşük metastaz potansiyeline sahiptirler. Tip3 mide NET hipergastrinemi ile ilişkisizdir ve yüksek metastaz potansiyeline sahiptirler. Mide NET gelişiminden gastrin, genetik faktörler, büyüme faktörleri ve matriks regülasyon proteinleri gibi birçok faktör sorumlu tutulmuştur. NET'lerin \%60-70'inde klinik bulgu oluşturan hormon fonksiyonu yoktur. Nonfonksiyonel tümörler tümörün büyümesi ve kitle etkisi ile karın ağrısı, ikter, bulantı ve kusma gibi semptomlar verirler (1). Olgumuzda karın ağrısı dışında herhangi bir semptom yoktu. Epigastrik ağrı nedeniyle yapılan gastroskopide tesadüfen tespit edilen polipler rezeke edilerek yapılan patolojik incelemede tanı konuldu. Hastada gastrin düzeyi bakılmamış olmakla birlikte uzun süre PPI kullanımı hipergastrinemiye neden olarak etyolojide rol oynamış olabileceği düşünüldü. 
Günümüzde en uygun tedavi primer lezyonun endoskopik veya cerrahi olarak çıkarılmasıdır (6). Tümörün büyüklüğü bir cm'den küçük ve sayısı üç- beşten az ise tercihen endoskopik polipektomidir $(7,8)$. Tümör bir cm'den büyük ve sayısı beşten fazla ve uzak metastaz yok ise tercih edilen tedavi cerrahi olarak tümörün çıkarılmasıdır (9). Uzak metastaz saptanan mide karsinoid tümörlü hastalarda diğer NET’ler gibi medikal, kemoterapi, hedeflenmiş radyoaktif tedavi, girişimsel radyolojik tedavi seçenekleri mevcuttur (9). Olgumuzda tespit edilen 2 adet polip; poliplerin 1 cm'den küçük ol- ması ve metastaz tespit edilmediği için polipektomi ile tedavi edildi ve takibe alınd.

Endoskopisinin yaygın kullanımı, biyopsinin hemen hemen rutin hale gelmesi ve histopatolojik tanı yöntemlerindeki gelişmeler nedeniyle mide NET polipleri giderek daha sık oranda tespit edilmektedir. Gastroskopide saptanan poliplerde, NET olasılığı akılda tutulmalıdır, tanı patolojik olarak özel boyamalar ile konulur. Bir cm'den küçük ve sayısı beșten az mide NET'lerde endoskopik polipektomi yeterlidir.

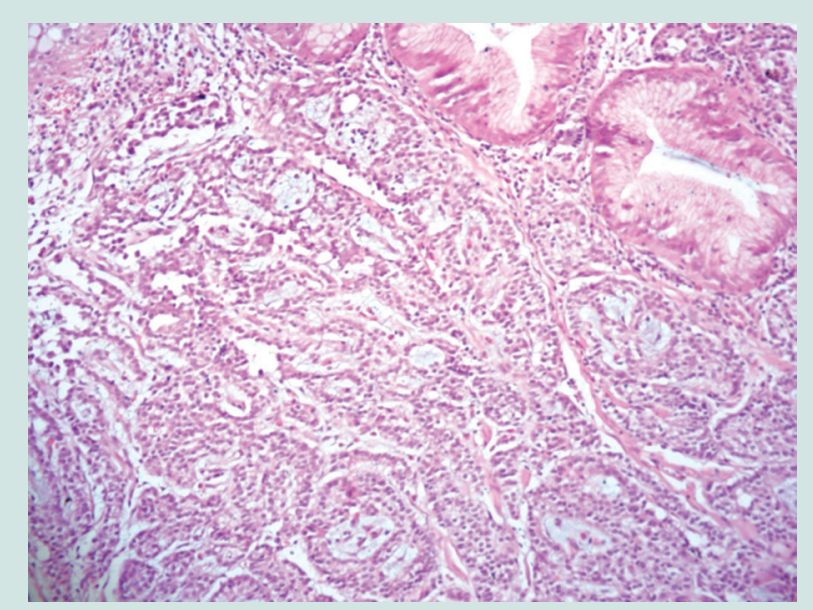

Resim 1. Mide fundus mukozasında lamina propriada nestler ve glandüler yapılar oluşturan oval yuvarlak nükleuslu eozinofilik stoplazmalı uniform monoton hücrelerden oluşan karsinoid tümör izlenmektedir (hematoksilen eozin x 200).

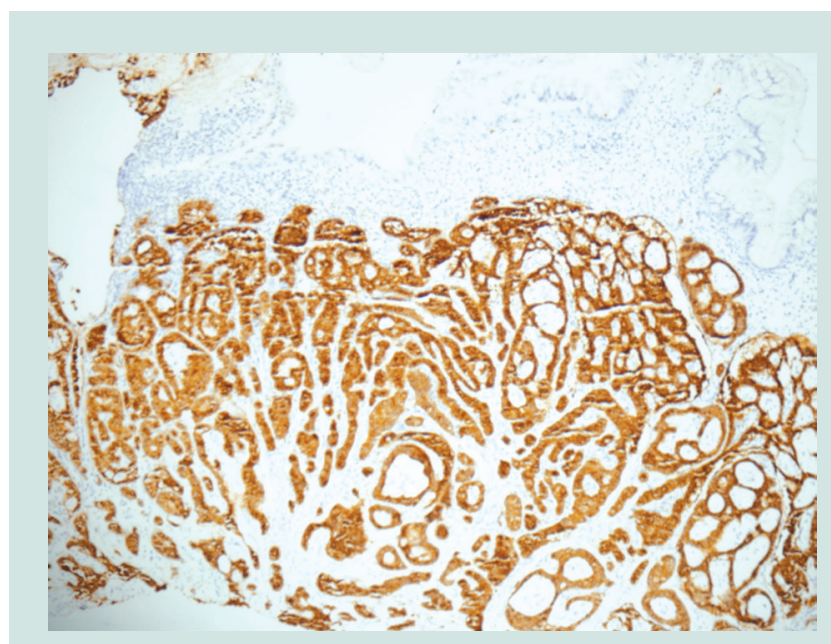

Resim 2. Kromogranin ile yapılan immünohistokimyasal çalışmada tümöral hücrelerin kuvvetli pozitif boyandığı izlenmektedir (kromogranin $\times 100$ ).

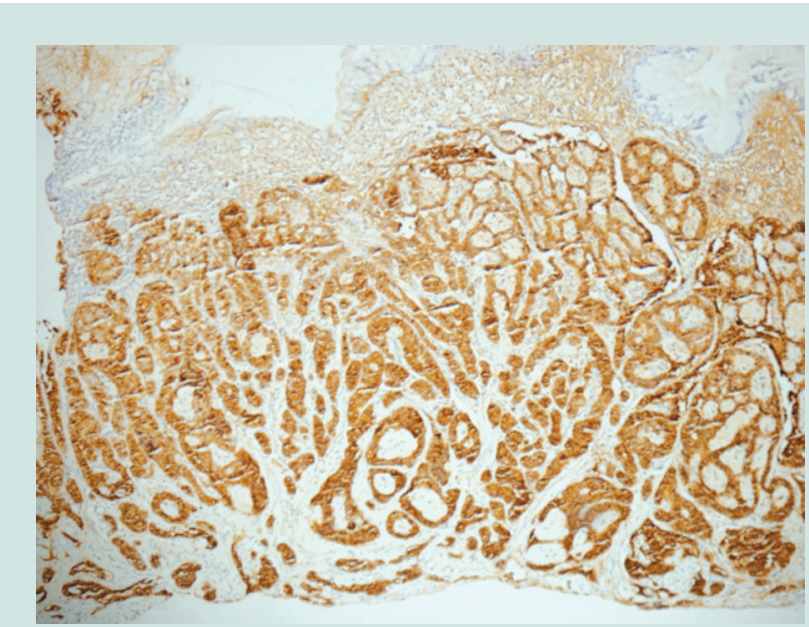

Resim 3. Sinaptofizin ile yapılan immünohistokimyasal çalışmada tümöral hücrelerin kuvvetli pozitif boyandığı izlenmektedir (sinaptofizin $\times 100$ ).

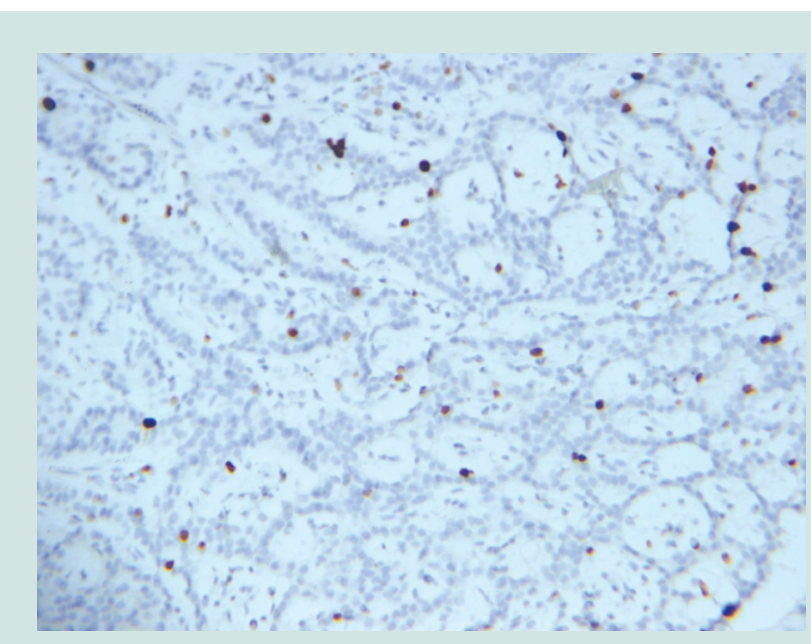

Resim 4. Ki67 ile yapılan immünohistokimyasal çalışmada tümöral hücrelerin \%5'inde pozitif nükleer boyanma izlenmektedir (Ki67 x 400). 


\section{KAYNAKLAR}

1. Hemminki K, Li X. Incidence trend sand risk factors of carcinoid tumors. A nation wide epidemiologic study from Sweden. Cancer 2001;92:2204-10.

2. Mougey AM, Adler DG. Neuroendocrine tumors: Review and clinical update. Hospital Physician 2007;51:12-20.

3. Yao JC, Hassan M, Phan A, et al. One hundred years after carcinoid: epidemiology and prognostic factors for neuroendocrine tumors in 35.825 cases in United States. J Clin Oncol 2008;26:3063-72.

4. Modlin IM, Lye KD, Kidd M. A 5-decade analysis of 13.715 carcinoid tumors. Cancer 2003;97:934-59.

5. Modlin IM, Lye KD, Kidd M. A 50-year analysis of 562 gastric carcinoids: small tumor or larger problem? Am J Gastroenterol 2004;99:23-32.
6. Solcia E, Fiocca R, Sessa F, et al. Morphology and natural history of gastric endocrine tumours. In: R. Hakansonand F. Sundler, Editors, Thestomach as an endocrine organ, Elsevier, Amsterdam 1991:473-98.

7. Arslan I, Uyanıkoğlu A, Aydoğan T, Yenice N. Otoimmün hepatite bağlı karaciğer sirozu ve gastrointestinal nöroendokrin tümör birlikteliği olan nadir bir olgu. Yeni Tip Dergisi 2014;31:128-30.

8. Demir M, Ataseven H, Gen R. Tip 1 mide karsinoid tümörün endoskopik polipektomi ile tedavisi: Bir olgu sunumu ve literatürün incelenmesi MN Dahili Bilimler 2009;1:31-36.

9. Ilhan E, Yıldırım M, Selek E, et al. Midenin multipl karsinoid tümörü: Olgu sunumu. Ege Tip Dergisi 2004;43:65-7.

10. Pinchot SN, Holen K, Sippel RS, Chen H. Carcinoid tumors. Oncologist 2008; 13:1255-69. 